ISSN:1308-8173

Geliş Tarihi: 13.05 .2019
E-ISSN: 1308-8505

Kabul Tarihi: 10.03 .2020
YIL: 2020

Online Yayın: 30.03.2020

ÖZGÜN ARAŞTIRMA
Cilt: 35 Sayı: 1 Sayfa: $61-76$

Doi: $10.24988 /$ ije.202035105

\title{
Endüstri 4.0 ve Yaşlı Çalışanların İstihdam Edilebilirliği *
}

\author{
Ayşenur ÖKTEM ÖZGÜR ${ }^{1}$ Tunç DEMIRBILLEK ${ }^{2}$ \\ Özet
}

Nüfusun yaşlanması ile birlikte hızlı teknolojik yenilikler, işin geleceğini dönüştürmektedir. Endüstri 4.0 olarak nitelendirilen teknolojik dönüşüm bağlamında, sistem karmaşıklığının artması ve fiziksel çalışma ortamının giderek daha fazla otomatik hale gelmesi, yeni işler ile ilgili görevlerde karmaşık bilgiyi uygulama, yeni bilgi oluşturma ve bilgiyi aktarma gibi becerileri gerekli kılmaktadır. Bu durum, yeterli bilgi ve iletișim teknolojisi (BIT) becerisine sahip olmayan yaşlı çalıșanların istihdam edilebilirliğini olumsuz etkileyebilmektedir. Ancak, günümüzde beklenen yașam süresinin artmasıyla daha fazla yaşlı çalışan aktif olarak işgücü piyasasında yer aldığı için, teknolojik dönüşüm, işletmeler ve çalışanlar için esnek kariyer modelleri ve yaş dostu çalışma ortamları geliştiren politikaları mümkün kılmakta ve talep etmektedir. Dolayısıyla, Endüstri 4.0, yaşlı çalışanların istihdam edilebilirliği açısından birtakım tehditler içerirken, çeşitli teknolojik sistemlerle onların istihdamına katkı da sağlayabilmektedir. Buradan hareketle, çalışmada ilk olarak Endüstri 4.0 kavramı ve işin yapısı ve beceriler üzerine etkileri incelenecektir. Daha sonra, Endüstri 4.0 bağlamında yaşlı çalışanlar ve yaşlı çalışanlara yönelik uygulamalar irdelenecektir.

Anahtar kelimeler: Endüstri 4.0, Yaşlanan İşgücü, Yaşlı Çalışan, İstihdam Edilebilirlik, İşin Yapısı, Beceriler Jel Kodu: J11, J14, 033

\section{Industry 4.0 and Employability of Older Workers}

\begin{abstract}
With the aging of the population, rapid technological innovations transform the future of work. In the context of technological transformation, which is defined as Industry 4.0, increasing system complexity and increasingly automated physical work environment requires skills such as applying complex information, creating new information, and transferring information in new work tasks. It may adversely affect the employability of older workers who do not have sufficient information and communication technology (ICT) skills. However, with the increasing life expectancy in today, a large number of older workers actively participate in the labour market. For this reason, technological transformation makes possible and demands flexible career models and policies that develop age-friendly working environments for organisations and workers. While Industry 4.0 has a number of threats especially for the older workers, it can contribute to their employment with various technological systems. From this point of view, firstly the concept of Industry 4.0 and its effects on nature of work and skills will be examined in this study. Then, older workers in the context of Industry 4.0 and applications for older workers will be examined.
\end{abstract}

Keywords: Industry 4.0, Aging Workforce, Older Worker, Employability, Nature of Work, Skills Jel Codes: J11, J14, 033

\section{GíRiş}

Günümüzde endüstri sonrası toplumun geldiği aşama Dördüncü Endüstri Devrimi ya da Endüstri 4.0'dır. Bu devrim yalnızca temel teknik ve ekonomik değişiklikleri içermeyip, işgücünün çalışma yaşamındaki rollerini de sürekli değişime uğratmaktadır. Dünyada, robotik teknoloji ve işyerlerinin bilgisayarlaşması, tüm profesyonel ve sosyal siniflardan çalışanlar için yeni zorluklar ortaya çıkarmaktadır. Değişen piyasa talepleri

\footnotetext{
* Bu makalede bilimsel araştırma ve yayın etiği ilkelerine uyulmuştur. / In this article, the principles of scientific research and publication ethics were followed.

Bu makale 6. Uluslararası Sosyal Beșeri ve İdari Bilimler Sempozyumu'nda (18-20 Nisan 2019 - Alanya/Antalya) sözlü olarak sunulan "Endüstri 4.0 ve Yaşlanan İşüucü" başllklı özet bildirinin geliştirilmiş halidir.

ATIF ÖNERİSI (APA): Öktem Özgür, A., Demirbilek, T. (2020). Endüstri 4.0 ve Yaşlı Çalışanların İstihdam Edilebilirliği. İzmir İktisat Dergisi. 35(1). 61-76. Doi: 10.24988/ije.202035105

${ }^{1}$ Araș. Gör., Karamanoğlu Mehmetbey Üniversitesi, İktisadi ve İdari Bilimler Fakültesi, Çalışma Ekonomisi ve Endüstri İlişkileri Bölümü EMAIL: aoktem@kmu.edu.tr ORCID: 0000-0002-9011-9704

2 Prof. Dr., Dokuz Eylül Üniversitesi, İktisadi ve İdari Bilimler Fakültesi, Çalışma Ekonomisi ve Endüstri İlişkileri Bölümü EMAIL: t.demirbilek@deu.edu.tr ORCID: 0000-0001-5384-6016
} 


\section{A. ÖKTEM ÖZGÜR - T. DEMIRBILLEK}

ve yeni teknolojiler, endüstriyel çalışma sisteminde çeşitli değişikliklere yol açan olanakları teşvik etmektedir. Daha kısa yaşam döngüleri ile bireyselleştirilmiş ürünler için artan talep nedeniyle, otomatik seri üretim artık ekonomik açıdan uygun değildir. Üretim sisteminin esnekliği, hızı ve üretkenliği, günümüzde küreselleşen piyasada rekabet etmek için en önemli faktörler olarak düşünülmektedir. Ürün çeşitliliğindeki artışla birlikte üretimdeki karmaşıklı da artmaktadır. Söz konusu karmaşıklıkla baş edebilmede, yenilikçi teknolojiler önemli bir rol oynayacaktır. Ancak, yalnızca teknoloji değil, bireyler ve toplum da değișime uğramaktadır. Özellikle, nüfusun yaşlanması ve teknolojik yeniliklerin hız kazanması işin geleceğini dönüştürmekte, beklenen yaşam süresinin artmasıyla daha fazla yaşlı çalışan işgücü piyasasında yer almaktadır. $\mathrm{Bu}$ bağlamda, yapısı bakımından işgücü ortalama olarak yaşlanmakta ve dijitalleşen çalışma yaşamında işgücü talepleri değişime uğradıkça, işgücü giderek daha fazla destek ve mesleki eğitime ihtiyaç duymaktadır. Buradan hareketle, çalışmada ilk olarak Endüstri 4.0 olgusu ve işin yapısı ve beceriler üzerindeki etkileri incelenecek ve daha sonra, Endüstri 4.0 bağlamında yaşlanan işgücü ve yaşlı çalışanlara yönelik uygulamalar irdelenecektir.

\section{ENDÜSTRI 4.0 VE BILLEŞENLERİ}

Birinci Endüstri Devrimi, su ve buhar enerjili mekanik üretim sistemlerinin devreye girmesinden kaynaklanırken, İkinci Endüstri Devrimi elektriğin ve kitle üretimin uygulanmasıyla gerçekleşmiştir. Diğer yandan üretimi otomatikleştirmek için elektronik ile BİT'in yarattığı farklılıkla Üçüncü Endüstri Devrimi ortaya çıkmıştır. Son olarak, sayısallaştırma, dijitalleștirme ve siber fiziksel sistemler gibi ilgili teknolojilerin kullanılmasıyla ortaya çıkan Endüstri 4.0, enformasyon teknolojileri ile operasyonel teknolojilerin bir araya gelmesiyle dijital bir değer zinciri oluşturmayı ifade etmektedir (Aulbur ve diğerleri, 2016: 4; Davies, 2015: 2;
Thames ve Schaefer, 2016: 13; Marjanovic ve diğerleri, 2017: 93).

Endüstri 4.0, ilk kez 2011 yılında Hannover Fuarı'nda dile getirilmiştir. Fuara katılan uzmanlar tarafından, bilişim çağının modern yüzünün, üretim süreçlerine yepyeni bir boyut kazandırdığı ve yeni bir Endüstri Devrimi'nin yaşanmakta olduğu ifade edilmiştir. Alman Hükümeti'nin dile getirilen bu görüşleri, yeni bir endüstri stratejisi olarak ele almasıyla, 4 . Endüstri Devrimi kavramsal olmaktan öte, resmi bir nitelik de kazanmıştır (EBSO, 2015: 9). Dolayısıyla, mekanizasyon, elektrifikasyon ve otomasyondan sonra artık üretim endüstrisinde devrim yaratmayı hedefleyen "hayata geçirilebilir teknolojiler" (Enabler Technology) bulunmaktadır. Söz konusu teknolojiler, gelecekteki fabrikaların değişen piyasa talebi ve artan istikrarsızlıkla bașa çlkmalarına yardımcı olmalıdır. Bunun için geleceğin fabrikaları, makinelerin, ürünlerin, aletlerin, işgücünün ve hatta müşterilerin siber fiziksel üretim sistemlerine bağlandıkları "akıllı" fabrikalar olarak tasarlanmaktadır. $\mathrm{Bu}$ bağlı alt sistemler birlikte çalışarak bilgi ve veri alışverişi yapmakta ve değer oluşturma zinciri boyunca her bir süreç adımı için maksimum değer üretmeye çalışmaktadır (Wan ve diğerleri, 2015: 136). Değişimin itici güçleri (Petrillo ve diğerleri, 2018: 8; Wolf ve diğerleri, 2018: 70) Şekil 1'de gösterilmektedir.

Endüstri 4.0 kapsamında kullanılan temel teknoloji siber-fiziksel sistemler ve nesnelerin internetidir. Fiziksel dünya ile siber dünya arasındaki iletişim ve koordinasyonu içeren yapıların bütünü SiberFiziksel Sistemler (CPS) olarak adlandırılmaktadır (Wolf ve diğerleri, 2018: 70). Shafiq ve diğerleri (2015: 1149) CPS'yi, makinelerini, depo sistemlerini ve üretim tesislerini birleştiren işletmeler için küresel ağlar kurarak, fiziksel ve dijital dünyanın yakınsaması şeklinde tanımlamaktadır. Siberfiziksel sistemlerle makineler arasındaki gelişmiş iletişim, insan diyaloglarıyla eşdeğer 
hale getirilmektedir (Brettel ve diğerleri, 2014: 37; Rüßmann ve diğerleri, 2015: 6).

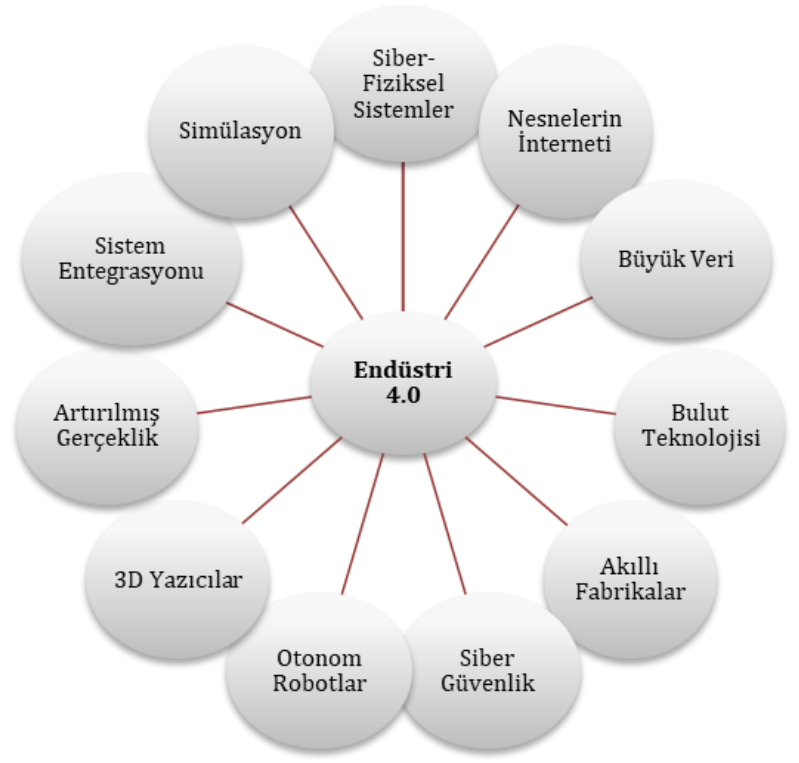

Şekil 1: Endüstri 4.0'ın İtici Güçleri

CPS, bağımsız, dahili ve akıllı bir sistem oluşturan bir dizi farklı etkinleştirme teknolojisidir. $\mathrm{Bu}$ nedenle, farklı ve fiziksel olarak uzak konular arasında entegrasyonu kolaylaştırabilir. $\mathrm{Bu}$ sistem üç ardışık senaryoyu mümkün kılmaktadır. Bunlar; veri oluşturma ve toplama, daha önce elde edilen verilerin hesaplanması ve toplanması, son olarak karar desteğidir. Söz konusu terim, algılayıcılar (sensör), harekete geçiriciler ve bir ă bağlantısı yoluyla veri üretebilen, böylece dahil olan çeşitli konular arasındaki mesafeleri azaltan birbirine bağlı nesnelerin varlığını içermektedir (Petrillo ve diğerleri, 2018: 8). Nesnelerin Interneti (IoT) gündelik fiziksel nesnelerin internete bağlanması ve kendilerini diğer cihazlarla tanımlayabilme fikri olarak ifade edilen bir bilgi işlem anlayışıdır (Nagy ve diğerleri, 2018: 8). Cihazların gerektiğinde birbirleriyle ve daha merkezi kontrol cihazlarıyla iletişim kurmasına ve etkileşim içinde olmasına olanak tanır (Rüßmann ve diğerleri, 2015: 6). Nesnelerin İnterneti araçları, bir ürün ya da üretim makinesinin bir işletme ağına bağlanmasını ve veri toplamasını ya da paylaşmasını sağlayan teknolojik bileşenlerdir. Söz konusu araçlar, algılayıcıları, radyo frekansı ile tanımlamayı, 3D tarayıcıları, kameraları vb.'lerini içerebilir (Nagy ve diğerleri, 2018: 8). Büyük veri, akıllı algoritmalarla yapılandırılmış ve yapılandırılmamış verilerin geniş toplama, işleme ve analizi ile ilgilidir. Bir diğer önemli teknoloji, açık sistemlerdeki büyük veri hacimlerini yönetmeyi ve üretim sistemi için gerçek zamanlı iletişim kurmayı sağlayan bulut bilgi işlemdir. Bulut bilgi işlem herhangi bir zamanda dünyanın her yerinden bilgiye erişim sağlar, böylece esnekliği arttırır (Petrillo ve diğerleri, 2018: 8). Akıllı fabrikada, veriler dijital olarak iletilir, bu nedenle siber güvenlik yeni endüstri devriminde kilit bir rol oynamaktadır. Makineinsan işbirliği ilişkisindeki karmaşıklık ve dinamik yönetim süreci nedeniyle, diğer teknolojilerin tam potansiyelini sağlamak için yüksek düzeyde siber güvenlik yapısı oluşturmak önemlidir (Lu, 2017: 7).

Endüstri 4.0, doğrudan akıllı fabrika tarafından yönetilen ve kurumsal sistemin geri kalanına bağlı otomatik robotların kullanımını içermektedir. İşlem otomatik olarak siber-fiziksel sistemler tarafından gerçekleştirilir. Genel olarak, otomatik robotlar ergonomik olarak zor, yorucu ya da karmaşık işler için kullanılmaktadır ve daha özerk, esnek ve işbirlikçi olmaları için geliştirilmektedir. Böylece, birbirleriyle etkileșim kuracak, insanlarla yan yana güvenli bir şekilde çalışacak ve onlardan öğrenecek duruma gelmektedirler (Rüßmann ve diğerleri, 2015: 4).

Teknolojik sistemlerin evrimi ve giderek artan bireyselleştirilmiş talepler, ek üretim tekniklerinin ve $3 \boldsymbol{D}$ baskının evrimine yol açmıştır (Petrillo ve diğerleri, 2018: 8-9). 3D yazıcı teknolojiler, birçok farklı malzeme ve yöntem bileșeni kullanarak üretim yapabilmektedir. 3D yazıcılardan; biyoorganik maddeler ile yapay damardan, böbreğe kadar gerekli insan dokuları ve müzik aletlerinden, İngiliz anahtarına kadar neredeyse her şey üretilebilmektedir. Geliştirilecek dev yazıcılar ile çok katlı binaların yapılması dahi olasılıklar 


\section{A. ÖKTEM ÖZGÜR - T. DEMIRBBILEK}

dahilindedir. 3D yazıcılar ile yaratıcı fikirler ve tasarımlar gerçek modellere, ilk ve son ürünlere hızlı bir șekilde dönüşebilecektir (EBSO, 2015: 11-12). Artırılmıs gerçeklik ise, ses, video, grafik ya da GPS verileri gibi bilgisayar tarafindan üretilip duyusal girdi ile artırılıp canlandırılan elemanların fiziksel, gerçek dünya ortamıyla birleștirilmesiyle oluşturulan yeni bir algı ortamının canl, doğrudan ya da dolaylı bir görünümüdür (Kahraman, 15.02.2019). Artırılmış gerçeklik, bilgisayar tarafından üretilen ek bilgilerin gerçek ortama entegrasyonu anlamına gelmektedir (Paelke, 2014: 1). Artırılmış gerçeklikle insan duyusuna hitap edecek ve hislerini harekete geçirecek girdiler, bilgisayar tarafından değişiklik yapılıp zenginleştirilir ve ortaya çıkan yeni gerçeklik kullanıcının algısına sunulur. Zenginleştirme gerçek zamanlı gerçekleşir ve çevredeki öğeler ile etkileşim içindedir. Artırılmış gerçeklik ile kullanıcı gerçeklik ortamını oluşturan bilgiler ve diğer öğelerle etkileşime girebilir. Bulunulan çevreyle ilgili yapay bilgi ve öğeler gerçek dünyayla bağdaşabilir (Kahraman, 15.02.2019). Sistem

Entegrasyonu, birden fazla sistemin bir araya getirilerek tek bir sistem olarak çalıșmalarını sağlamaktadır. Sistem tümleștiricileri, bilgisayar ağları, kurumsal uygulama entegrasyonu, iş-süreç yönetimi ya da programlama gibi çeşitli teknikleri kullanarak ayrık sistemleri bir araya getirirler (EBSO, 2015: 21). Son olarak, simülasyon sistemleri ve yazılımlar da çok kullanılmaktadır. $\mathrm{Bu}$ araçlar sayesinde, sistem giriş ve çıkışını gerçek zamanlı olarak analiz ederek ve incelenen süreçle ilgili ayrıntılı bir rapor alarak iş sistemlerini ve üretim süreçlerini canlandırmak mümkündür (Rüßmann ve diğerleri, 2015: 5; Shafiq ve diğerleri, 2015: 1149; Petrillo ve diğerleri, 2018: 9).

Söz konusu teknolojiler, işletmelerin değişen piyasa talebini karşılayabilmelerine ve dünya çapında rekabetçi olmalarına yardımcı olacaktır. $\mathrm{Bu}$ teknolojiler temel olarak bireylerin yerine geçecek teknolojiler olmaktan ziyade, insan gücü için destek teknolojileri olarak kabul edilmelidir. Daha önce de bahsedildiği üzere, teknoloji ürünlerin talep tarafını da değiştirmektedir. Ürünler giderek daha akıllı olacağından, birçok farklı disiplin Ar-Ge ve üretimde bir araya gelecektir. Elektrik ve makine mühendislerinden yazılım uzmanlarına ve endüstriyel tasarımcllara kadar farklı etkiler, işlevselliği ve gelecekteki ürünlerin görünümünü değiștirecektir. $\mathrm{Bu}$ durum, çalışanların kendileri için gerekli disiplinler arası bilgi ile baş edebilmek için daha geniș bir yelpazede becerilerini geliştirmeye ihtiyaç duydukları anlamına gelmektedir (Kleindienst ve diğerleri, 2016: 2).

\section{ENDÜSTRİ 4.0'IN İŞIN YAPISI VE BECERILLER ÜZERINE ETKILLERİ}

Endüstri 4.0, üretim süreçlerinde ve iş ile ilgili görevlerde önemli değişikliklere yol açmaktadır. Çalışanlar, makineyle işbirliği yapmak gibi karmaşık ve dolaylı görevler yerine çalışma sürelerini çok daha fazla paylaşacaklardır (Siemens, 2013: 11). Çalışanların temel görevi, yüksek otomasyonlu karmaşık süreçlerin yanı sıra, makinelerin gözetimi ve etkin bir şekilde çalışması ile ilgili gözlem ve düzenleme olacaktır. Bu nedenle, bilgi ve büyük miktarda veri ve makinelerle iletişim kurmak, gelecekteki işler ile ilgili görevlerin temel unsurları olacaktır (Kleindienst ve diğerleri, 2016: 2).

Hızlı gelişmeler yalnızca değer zincirlerini ve endüstrileri etkilemekle kalmamakta, aynı zamanda işin temel yapısında da değișim yaratmaktadır. Makine öğrenmesi, yapay zeka ve robotik süreç otomasyonu günümüzde ortaya çıkan sayısız teknolojiden yalnızca birkaçıdır. Söz konusu teknolojilerin çoğu hala gelişme aşamasındadır ve 2030 yılına kadar küresel işletmelerde büyük olasılıkla çoğalacaklardır. $\quad \mathrm{Bu}$ teknolojilerin kullanımının artması, tekrarlayan işleri ve düşük vasıflı emeği ciddi şekilde etkileyecektir. Rutin ve beden gücüne dayalı işler 1970'lerden bu yana düşüş eğilimindedir ve bugünkü teknolojik gelişmelere bağlı 
olarak bu düşüşün daha da hızlanacağı açıktır (Basu ve diğerleri, 2018: 10). Dünya Ekonomik Forumu'nun İşlerin Geleceği Raporu'nda, 2015-2020 yılları arasında 7.1 milyon işin ortadan kalkacağı ve yalnızca 2 milyon yeni iş yaratılacağı belirtilmektedir. Üretim ve imalatın yanı sıra ofis ve idari işlerde de ciddi iş kayıpları olurken, finansal işlemlerden yönetime ve mühendisliğe kadar farklı alanlarda yeni işler yaratılacaktır (World Economic Forum, 2016: 13). Bu anlamda, günümüzde veri analistliği, veri madenciliği, dijital pazarlama ve elektronik ticaret uzmanlığı gibi yeni ișler yaratılırken (Degryse, 2016: 23), pek çok fabrika çalışanı, sekreter ve teslimat personeline ait görevlerin çoğunu bilgisayarların ve robotların üstlendiği görülmektedir. Söz konusu gelişmelerin bir sonucu olarak işgücü piyasasında üç temel dönüşüm öngörülmektedir (World Economic Forum, 2016: 13):

1. Çalışmanın İşten Ayrıştırılması: İşler artık çalışma için örgütlenme birimi değildir; aksine, işi yapmak için en uygun kişiye göre insan ve makine arasında görevlerin yeniden dağıtılması söz konusudur.

2. Yeni Calıșma, Yeni Beceriler: Yeni teknolojilerin yaygınlaşması ile birlikte, yeni teknolojilerin tasarımı, geliştirilmesi ve bakımıyla ilgili yeni roller ortaya çıkacaktır.

3. Yüksek Bilişsel Karmaşıklık: Geleceğin işgücü, daha yüksek bilişsel ve duygusal karmaşıklık gerektiren görevleri yürütecektir.

Gelecekteki üretim süreçleri, farklı ürün seçeneklerini üretmek için çeşitli şekillerde birleştirilebilen birçok küçük standartlaşmış adımdan oluşacaktır. Yeni üretim biçimi, daha yüksek iş karmaşıklığına ve işgücü için bilgi talebinin artmasına neden olmaktadır (Wolf ve diğerleri, 2018: 67). Dolayısıyla, yapısal değişim, bazı meslek ve sektörlerde istihdam olanakları yaratmakta, diğerlerinde firsatları azaltmakta ve böylece işgücü piyasasında ihtiyaç duyulan beceri türlerini değiştirmektedir. Son on yılda, bazı ülkeler ekonomilerinin diğerlerine göre daha hızlı dönüştüğünü görerek, çalışanların yeniden eğitimine daha fazla ihtiyaç duyulduğunu belirtmektedir (OECD, 2019: 23). 'İşlerin Geleceği' araştırmasına göre, bireylerin değişen sürece ayak uydurmak için hızla gelişmesi gerekecektir. Nitekim, Dünya Ekonomik Forumu bugünün (2016 yılı) becerilerinin yalnızca \%35'inin 2020'de uygulanabileceği konusunda uyarmaktadır. İleri teknolojilerin geliştirilmesi ve sonuçta ortaya çlkan beceri boşlukları, düşük veya temel becerilere sahip çalışanların işsiz kalmalarına neden olabilir. Araștırmaya göre, günümüzde önemli sayılmayan bazı becerilerin 2020'de çoğu meslekte arzulanan temel beceri setinin üçte birini oluşturması beklenmektedir. Verilerle çalışma ve veri tabanl kararlar alma becerisi gelecekteki işlerde önemli bir rol oynamaktadır. Endüstri 4.0 bağlamında, çalışanların yeni beceriler kazanmaları gerektiği halde, mevcut teknik ve mesleki eğitimde kazanılan temel nitelik ve beceriler halen önemli kalacaktır ve endüstri teknolojisinin gelişimi ile güncellenmek durumundadir (World Economic Forum, 2016: 20). Tablo 1'de Endüstri 4.0 sürecinde gerek duyulacak önemli beceriler üç ana kategoriye ayrılmıştır.

Endüstri 4.0 sistem bileșenleri arasındaki otomasyon ve ara bağlantı nedeniyle daha karmaşık sistemler içerdiğinden, sistem yeterliliği üretim çalışanları açısından temel bir nitelik olacaktır. Sistem yeterliliği, üretim sisteminin unsurlarını tanımayı, sistem sınırlarını tanımlamayı, işlevlerin ve sistem içindeki ilişskilerin anlaşılmasını ve böylece sistem davranıșını tahmin edebilmeyi içermektedir.

Gehrke ve diğerleri (2015: 13) tarafından gerçekleștirilen Alman ve Amerikan bakış açısıyla Geleceğin Fabrikasında Nitelikler ve Becerilerin Tartışılması Projesi kapsamında, özel bir önceliklendirme tekniği kullanılarak geleceğin işletmeleri için önemli olacak niteliklerin ve becerilerin bir listesi, Tablo 2'de gösterilmektedir. Beceriler, bireysel ve teknik beceriler olmak üzere ikiye ayrılmaktadır. 


\section{A. ÖKTEM ÖZGÜR - T. DEMIRBILLEK}

Tablo 1: Endüstri 4.0 Sürecinde Gerek Duyulacak Önemli Yetenekler ve Beceriler

\begin{tabular}{|c|c|c|c|}
\hline Yetenekler & Temel Beceriler & \multicolumn{2}{|c|}{ Çapraz Fonksiyon Becerileri } \\
\hline $\begin{array}{l}\text { Bilişsel Yetenekler } \\
\text { - Bilişsel Esneklik } \\
\text { - Yaratıcılık } \\
\text { - Mantıksal Akıl Yürütme } \\
\text { - Sorun Duyarlılığı } \\
\text { - Matematiksel Akılcılık } \\
\text { - Görselleştirme }\end{array}$ & $\begin{array}{l}\text { İçerik Becerileri } \\
\text { - Aktif öğrenme } \\
\text { - Sözlü anlatım } \\
\text { - Okuduğunu anlama } \\
\text { - Yazılı anlatım } \\
\text { - BİT okuryazarlığı }\end{array}$ & $\begin{array}{l}\text { Sosyal Beceriler } \\
\text { - Başkaları ile koordinasyon } \\
\text { - Duygusal zeka } \\
\text { - Müzakere } \\
\text { - İkna } \\
\text { - Hizmet oryantasyonu } \\
\text { - Başkalarına eğitim ve } \\
\text { öğretim verme }\end{array}$ & $\begin{array}{l}\text { Kaynak Yönetimi } \\
\text { Becerileri } \\
\text { - Mali kaynaklar yönetimi } \\
\text { - İnsan yönetimi } \\
\text { - Zaman yönetimi }\end{array}$ \\
\hline \multirow[t]{2}{*}{$\begin{array}{l}\text { Fiziksel Yetenekler } \\
\text { - Fiziksel güç } \\
\text { - El becerisi } \\
\text { - El yatkınlığı }\end{array}$} & $\begin{array}{l}\text { Süreç Becerileri } \\
\text { - Aktif dinleme } \\
\text { - Eleştirel düşünme } \\
\text { - Kendini ve diğerlerini } \\
\text { izleme }\end{array}$ & $\begin{array}{l}\text { Sistem Becerileri } \\
\text { - Karar verme } \\
\text { - Sistem analizi }\end{array}$ & $\begin{array}{l}\text { Teknik Beceriler } \\
\text { - Ekipman bakım, onarım } \\
\text { - Çalıștırma ve kontrol } \\
\text { - Programlama } \\
\text { - Kalite kontrolü } \\
\text { - Sorun Giderme } \\
\text { - Teknoloji ve kullanıcı } \\
\text { deneyimi tasarımı }\end{array}$ \\
\hline & & \multicolumn{2}{|c|}{$\begin{array}{l}\text { Karmaşık Sorun Çözme Becerileri } \\
\text { Karmașık sorun çözümü }\end{array}$} \\
\hline
\end{tabular}

Kaynak: World Economic Forum, 2016: 20.

Tablo 2: Geleceğin Vasıflı İşgücünün Sahip Olması Gereken Niteliklerin ve Becerilerin Öncelik Sinıflandırması

\begin{tabular}{|c|c|c|c|}
\hline & "Olmak zorunda" & "Olmalı" & "Olabilir" \\
\hline \multirow{5}{*}{ 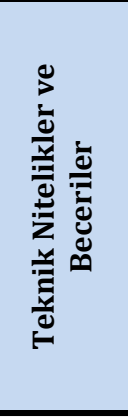 } & Veri ve bilgi işleme ve mantıksal analiz & Bilgi Yönetimi & $\begin{array}{c}\text { Bilgisayar programlama / } \\
\text { kodlama yetenekleri }\end{array}$ \\
\hline & Bilișim teknolojileri (BT) bilgi ve yetenekleri & $\begin{array}{c}\text { Teknolojiler ve organizasyonlar } \\
\text { hakkında disiplinlerarası / genel bilgi }\end{array}$ & $\begin{array}{c}\text { Teknolojiler hakkında uzmanlık } \\
\text { bilgisi }\end{array}$ \\
\hline & İstatistiksel bilgi & $\begin{array}{l}\text { Üretim faaliyetleri ve süreçleri } \\
\text { konusunda uzmanlaşmış bilgi }\end{array}$ & Ergonomi için farkındalık \\
\hline & Örgütsel ve süreçsel anlayış & $\begin{array}{l}\text { BT güvenliği ve veri koruması için } \\
\text { farkındalık }\end{array}$ & Yasal işlerin anlaşılması \\
\hline & $\begin{array}{l}\text { Modern arayüzlerle etkileşime girebilme } \\
\text { (insan-makine / insan-robot) }\end{array}$ & Yeni teknolojilere güven & \\
\hline \multirow{5}{*}{ 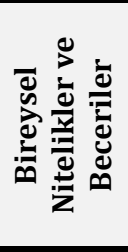 } & Öz yönetim ve zaman yönetimi & & \\
\hline & Uyarlanabilirlik ve değișime uyum yeteneği & $\begin{array}{c}\text { Sürekli gelişim ve yaşam boyu öğrenme } \\
\text { için isteklilik }\end{array}$ & \\
\hline & Takım çalışması yeteneği & & \\
\hline & Sosyal beceriler & & \\
\hline & İletişim becerileri & & \\
\hline
\end{tabular}

Kaynak: Gehrke ve diğerleri, 2015: 13.

Tablo 2'den de anlaşılacağı üzere, bilişim teknolojileri, bilgi ve veri işleme, örgüt ve süreç anlayışı ve makinelerle etkileşim şeklindeki teknik becerilerinin yansıra, kişinin kendini ve zamanı yönetmesi, değişime uyum sağlama ve takım çalışması biçimindeki bireysel becerileri modern üretim sistemlerinde çalışanlar için zorunlu beceriler olarak ortaya çıkmaktadır. Diğer yandan, yaşam boyu öğrenme için isteklilik ve disiplinler arası düşünme sahip olunması gereken önemli becerilerdir. Esas itibariyle, bu durum sanayi çalışanlarının da bilgi çalışanları olması gerektiği anlamına gelmektedir. İşin gerektirdiği faaliyetlerin önemli bir bölümü (karmaşı) bilgiyi uygulama, bilgiyi arama, yeni bilgi yaratma ya da yeni bilgileri paylaşma ve iletmeyi içermektedir (Kleindienst ve diğerleri, 2016: $2,3)$.

\section{YAŞLANAN İŞGÜCÜ: FIRSATLAR VE TEHDITLER}

Dünya genelinde tüm ülkeler, nüfuslarındaki yaşlı bireylerin sayısında ve oranında artış yaşamaktadır. Birleşmiş Milletler'in Dünya 
Nüfus Yaşlanma Raporu'na göre, Dünya genelinde 60 yaş ve üzeri nüfus 2017'de 962 milyonu aşmıştır ve söz konusu nüfus 1980 yılında 382 milyon iken, 2.5 kat artış göstermiştir. Yaşlı birey sayısının 2050 yılına kadar yaklaşık 2.1 milyar düzeyine ulaşacağı tahmin edildiğinden, ikiye katlanması beklenmektedir (United Nations Department of Economic and Social Affairs Population Division, 2017: 1).

Dünya nüfusunun yaşlanıyor olması, günlük yaşamın tüm alanlarında etki yaratmaktadır. $\mathrm{Bu}$ nedenle, Birleşmiş Milletler söz konusu demografik değişimi "yirmi birinci yüzyılın en önemli toplumsal dönüşümlerinden biri” olarak tanımlamaktadır. Nitekim, 2050 yılına kadar dünya nüfusunun bește birinin 60 yaş ve üzerinde olacağı öngörülmektedir (United Nations Department of Economic and Social Affairs Population Division, 2015: 1). Söz konusu gelişmeyi yönlendiren temel eğilimler, doğum oranlarındaki düşüşün yanı sıra, yaşam beklentisinin uzaması ve daha iyi eğitim ve doğum kontrolünden kaynaklanmaktadır (Schinner ve diğerleri, 2017: 537).

Belirtilen demografik eğilimlerle, genişleyen yaş piramidinin bir sonucu olarak, işgücü piyasasına katılan genç çalışanların sayısı düşecek ve çok sayıda yaşlı çalışan ${ }^{3}$ da çalışma yaşamından ayrılacaktır. İyi eğitimli ve yüksek vasıflı çalışanlar ekonominin başarısında anahtar faktördür. Eğitimli ve vasıflı çalışanların emekli olmasıyla, endüstriyel rekabet gücünün korunması için gerekli önemli bilgiler de işletmeleri terk edecektir (OECD, 2019: 25). İşletmeler sahip oldukları işgücünün yaş yapısında meydana gelen bu değişimlerle mücadele etmek durumundadır.

\footnotetext{
3 "Bourne, (1982) ve Warr (2000), "yaşlı işgücü" ya da "yaşlı çalışan" kavramını, çalışma alanına bağlı olarak değişiklik göstermekle birlikte, 40 yaşından 75 ve üstü yaşa kadar çalışma yaşamında aktif olarak yer alan bireyler olarak ifade etmektedir (Kooij, 2010: 29). Öte yandan, kurumlardaki yaşlı çalışanları inceleyen araştırmacılar, çoğu zaman eski veya güncelliğini kaybetmiş olan bilgi, beceri ve tutumlara atıfta bulunarak yașlı çalıșan tanımında eșik değeri 40 veya 45 yaș olarak belirlemişlerdir (Marmora ve Ritter, 2014: 2; Axelrad ve diğerleri, 2013: 1059). İşgücü piyasasına katılım ile ilgili
}

İșletmelerin başarısı giderek yașlı çalışanlarının sahip olduğu bilgi, beceri ve deneyimlerine bağlı olmaktadır. Bu nedenle, işletmeler yaşlı çalışanların daha uzun süre çalışabilmeleri ve yeni teknolojik gelişmeler ile geleceğin zorluklarını aşabilmeleri için onları yeniden eğitmenin yollarını bulmak zorundadır. Bu anlamda, mevcut işgücü eğitim yöntemlerini gözden geçirmek ve yaşlı işgücünün ihtiyaçlarına uyarlamak gerekmektedir (Schinner ve diğerleri, 2017: 538).

Demografik değişim nedeniyle işgücünün ortalama yaşı artmaktadır. Yaşlı çalışanlar genellikle sanayi işyerlerinde daha az güçlü ve daha az esnek grup olarak görülmektedir. Bununla birlikte, yaşlı çalışanlar mevcut işgücünün büyük bir kısmını oluşturmaya başlayacağı için, potansiyellerini tanımak, deneyimlerinden faydalanmak ve onları sürece başarılı bir şekilde entegre etmek özellikle önemlidir. Demografik değişimin en belirgin etkisi, toplumda ve endüstriyel çalışma ortamlarındaki yaşlı birey sayısının artmasıdır. Yaşlanma sürecinde birçok fiziksel, duyusal ve bilişsel beceri değişmekte, söz konusu değişim işgücünün çalışabilirliği ve işin gerekleri arasında bir uyumsuzluğa yol açmaktadır (Wolf ve diğerleri, 2018: 70). Yaşlanma, fiziksel, psikolojik ve sosyoekonomik geçmişte var olan farklılıkları güçlendiren bireysel bir süreçtir (Schieber, 2003: 47). Yaş ilerledikçe, insan vücudunda ve beyninde bazı değişiklikler meydana gelir ve bazıları çalışma ortamı için son derece önemlidir. Özellikle, duyusal beceriler, motor beceriler ve bilişsel yetenekler yaşla birlikte değişim gösterir. Bilișsel durumdaki bireyler arası değișkenlik büyük ölçüde kültürel ve

çalışmalarda ve uluslar arası raporlarda, "yaşlı çalışan" kavramı genellikle 50 veya 55 yaș ve üzeri çalışanları ifade etmek için kullanılmaktadır. Genellikle 50 ya da 55 yaş ve üzeri yaş grubunun eşik olarak seçilme nedeni, birçok ülkede bu yaş aralığında işgücünün ciddi düzeyde işsizlik deneyimi yaşamasıdır (OECD, 2005: 3). Çeşitli tanımlamalardan hareketle, çalışmada "yaşlı çalışan" kavramı 50 yaş ve üzeri işgücünü nitelemektedir. 
çevresel faktörler tarafından yönlendirilmektedir. Yaşlılıkta bireyler biyolojik temelli faktörler tarafından kısıtlanabilir. Ancak, değişim bireyden bireye değişmekle birlikte, farklı hızda gerçekleşmektedir (Lia ve Lindenberger, 2002: 777). Diğer yandan, çalışanlar da farklı hızlarda çalışırlar. Bu da, yaşlı çalışanların yaşlanma sürecinden bireysel olarak değișik ölçülerde etkilenebileceği anlamına gelmektedir. Bazıları karmaşı motor görevleri yerine getirebilirken, diğerleri yalnızca bilişsel yetenek gerektiren görevlerde iyi performans gösterebilirler. Dolayısıyla, çalışma konusunda görevlerin uyumu yaşlı çalışanlar için daha kritik bir öneme sahiptir (Czaja ve diğerleri, 2006: 335).

Özellikle, fiziksel kabiliyetlerin azalması (örneğin kas gücü ya da ince motor beceriler), duyusal yetilerin azalması (örneğin duyma ya da görme duyusu), bilişsel ve zihinsel işlevlerin değişimi (örneğin, zihinsel esneklik, bilgi işlem hızı, kısa süreli belleğin azalan işlevi) ve aynı anda işlenebilecek bilgi miktarının azalması gibi değişikliklerin yanı sıra, yeni şeyler öğrenmek ve değişimlere uyum sağlamak ya da yeni işletme araçları ve teknolojiler ile çalışmak için daha az istekli olmak endüstriyel istihdam edilebilirliği de olumsuz yönde etkileyebilmektedir. Diğer yandan, yaşam ve iş deneyiminin artması ve sorun çözme stratejilerinin değişmesi, liderlik becerileri, kendini örgütleme becerileri, yeni ya da karmaşık durumlarda muhakeme yeteneği, sosyal ve takım çalıșması becerileri vb. yaşla birlikte artar (Wolf ve diğerleri, s. 70). Kısacası, yaşlandıkça kademeli olarak kaslar zayıflamakta, fiziksel olarak güç kaybı meydana gelmektedir (Peeters ve Emmerik, 2008: 357). Ancak, yaşlı çalışanın sahip olduğu pek çok yetinin gerileme eğilimi olmasına rağmen, genel kanının aksine bazı beceriler de daha belirgin ve etkin hale gelebilmektedir.

Günümüzde pek çok iş, ağırlıklı olarak bilişsel ve sosyal-duygusal yeterlilikler gerektirdiği için, fiziksel güç ve hızın düşmesi telafi edilebilmektedir. Teknolojik değișmeyle birlikte, özellikle el becerisine dayanan mesleklerden uzaklaşma yönündeki değişimin, çalışma performansında yaşla ilgili sağlık sorunlarının önemini azalttığ söylenebilmektedir (OECD, 1998: 138). Bu nedenle, işyerinde potansiyellerine göre performans gösterebilmeleri için, yașlı çalışanların görev tasarımına gereksinimi bulunmaktadır. İşyerleri ve iş ile ilgili görevlerin tasarımında, beceri ve yetkinliklerdeki yaşla ilgili değişiklikler dikkate alınmadığında, yaşlı bireyler verimli bir biçimde çalışamayabilir. Ancak, yaşlı nüfus ve dolayısıyla işgücü piyasasında da yaşlı çalışanların oranı arttıkça endüstriler gelecekte yaşlı çalışanlara başvurmak için bir yol bulmak ve onların deneyimleri gibi özel avantajlarından faydalanmak zorunda kalacağından iş ve işyeri tasarımı önemli hale gelmektedir (Wolf ve diğerleri, 2018: 70).

\section{ENDÜSTRİ 4.0 BAĞLAMINDA YAȘLI ÇALIŞANLAR}

Bir yandan dijital çağa doğru ciddi bir dönüşüm yaşanmaktayken, diğer yandan nüfus da yaşlanmaktadır. Çalışma çağ nüfusunun daralıyor olması, otomasyon gibi emeğin ötesinde alternatif verimlilik tekniklerine yönelmeye neden olmaktadır. Toplumsal yaşlanmanın etkilerine ilişkin bir araştırmada, yüksek yaşlanma oranları ile yüksek otomasyon oranları arasında anlamlı bir ilişki saptanmıştır. Söz konusu ilişki, üretim süreçlerinde robotların benimsenmesindeki artışın yaşlanmanın daha hızlı olduğu ülkelerde daha fazla olduğunu göstermektedir. Güney Kore bu durumu açıklamak için önemli bir örnektir. Güney Kore, 2017 yılının sonuna doğru dünyadaki en yüksek robot yoğunluğuna sahip ülke olmasının yanı sıra, aynı zamanda günümüz ve 2050 yılı arasında dünyanın en hızlı yaşlanacak ülkesi olarak tahmin edilmektedir (International Federation of Robotics, 2017: 20). Uluslararası Robotik Federasyonu'ndan robot verileri ile Birleşmiş Milletler'deki yaşlanma verilerini analiz eden Acemoglu ve Restrepo (2018: 2), endüstriyel robotların benimsenmesinde ülkeler arası farklılıkların \%40'ının yaşlanma ile açılklanabildiğini 
belirtmektedirler. Ayrıca, adı geçen araștırma sonuçları, yaşlanma hızlandıkça otomasyona uygun endüstrilerde verimliliğin artarken, emeğin bu sektörlerdeki gelir payının düşmesinin muhtemel olduğunu göstermektedir. Söz konusu ilişkilerin saptanması, yaşlı çalışanların geleceğin işgücü piyasalarındaki yerini anlamayı kolaylaştırır. Otomasyonun verimliliği artırma potansiyeli olmasına rağmen, emeğin oranını azaltma ve belirli becerilere sahip olmayan çalışanları da işinden etme olasılığı bulunmaktadır (Acemoglu ve Restrepo, 2018: 1-2). Bu nedenle, otomasyonun yaşlı çalışanlar üzerindeki etkisinin ne olacağı hususu araştırılmalıdır.

Beceri gerekliliklerinin farklı vasıfsız çalışma türleri arasında benzer kaldığı (eski tarım işleri ile yeni fabrika işleri arasındaki beceri farklılıkları genellikle azdı) ve verimliliğin arttığı daha önceki endüstriyel geçişlerin aksine, günümüzün geçiş süreci düşük ve temel vasıflı işgücünün üretkenliğini sürdürebilmek için daha dik bir öğrenme eğrisi ile karşı karşıya kalmasını gerektirecektir (Basu ve diğerleri, 2018: 13). $\mathrm{Bu}$ öğrenme eğrisi, çoğu BİT becerisine sahip olmayan yaşlı çalışanlar için özellikle zor olacaktır. Örneğin, bir bilgisayar, tablet ya da yeni bir yazılım kullanarak sorunları çözme ve işbirliği yapma yeteneği gibi. OECD tarafından yapılan kapsamlı bir araştırmaya göre, 55-65 yaş arası yetişkinlerin yalnızca yüzde 10 'u, (25-54 yaş arası yetişkinlerin yüzde 42'sine kıyasla) "yeni çok adımlı teknolojik görevleri tamamlayabilir" sonucuna ulaşılmıştır (OECD, 2016: 2). $\mathrm{Bu}$ nedenle, işletmeler ve hükümetlerin eğitim ve yaşam boyu öğrenmeye önem vermesi gerekmektedir (Basu ve diğerleri, 2018: 13). Ancak, günümüzde mevcut olan istihdam ve eğitim olanakları yaşlı çalışan kesimini oluşturan 50 yaş ve üzeri işgücü için etkin olamamaktadır. Bir danışmanlık şirketinin gerçekleştirdiği araştırmada, 50 yaş üstü milyonlarca bireyin işsiz olduğu ancak doğru firsatlar olursa çalışmak istedikleri vurgulanmaktadır (Lincoln, 2017: 8). Genellikle genç meslektaşlarına göre daha düşük işsizlik oranları yaşamasına rağmen, yaşlı çalışanlar istikrarlı ve anlamlı bir iş bulma konusunda engeller ile karşı karşıya kalmaktadır. Yaşlı çalışanlar, gençlere kıyasla daha uzun süreli işsizliğe maruz kalmaktadır ve aynı zamanda OECD verilerine göre, 25-54 yaş grubu işgücüne kıyasla belirli bir sürede (yıl/yıllar) yeniden istihdam edilme olasılıkları çok daha düşüktür (OECD, 2013: 20). 2017 yılı itibariyle 55-64 yaş grubu yaşlı çalışanların işsizlik oranları \%4.6 iken, uzun dönemli işsizlik oranları \%41.5 düzeylerine ulașmıștır (OECD, 2018: 276, 289). Buradan hareketle, yaşlı çalışanların işlerini kaybettiklerinde, yeni bir iş bulmak için oldukça zorlandıkları anlaşılmaktadır. Dolayısıyla, yaşlı çalışanlar istikrarlı bir iş bulmakta güçlük çektikleri için, yaşlandıkça yarı zamanlı ve düzensiz çalışma eğiliminde olmaktadır (Basu ve diğerleri, 2018: 14). 2015 yılında on altıncisı gerçekleştirilen Transamerica emeklilik anketinden elde edilen araştırma bulguları da bunu desteklemektedir. ABD'de 18 yaş ve üzeri 4550 tam zamanlı ya da yarı zamanlı çalışanla gerçekleştirilmiş araştırma sonuçlarına göre, çalışanların çoğunluğu 65 yaşından sonra da çalışmayı planlamakta ve \%14'ünün emekli olmak için hiçbir planı bulunmamaktadır. Yaşlı çalışanların \%50'den fazlası ise, emekli olsalar da tam zamanlı ya da yarı zamanlı olarak çalışmayı hedeflediklerini belirtmişlerdir (OECD, 2015: 8). İşgücü piyasasını erken terk eden 50 yaş ve üzeri bireylerin belirttiği en yaygın nedenler, uygun becerilerin eksikliği (Department for Work \& Pensions, 2017: 7), özellikle düşük ücretli ve düşük vasıflı işgücü için ihtiyaç fazlası duruma gelme (McNair, 2011: 22), bakım ve çalışma sorumlulukları arasında denge sağlayamama ve kronik sağlık sorunlarıdır. Ayrıca, yaşa yönelik ayrımcılık ve önyargı, çok sayıda yaşlı çalışanı sürekli öğrenme ve gelişimden alıkoymaktadır. 50 yaş ve üzeri olan bireyler artık yeni zorluklara karşı mücadele verebilecek dinamik ve aktif işgücü piyasası katılımcıları olarak görülmemektedir (McNair, 2011: 3). Yaşlı çalışanlar, yaş aldıkça 


\section{A. ÖKTEM ÖZGÜR - T. DEMIRBILLEK}

kendilerine eğitim verilme ihtimalinin düșük olduğunu ve işletmelerin genç çalışanlara öncelik verdiğini düşünmektedir. Buna ek olarak, işletmeler gelişmeye motive olmuş yaşlı çalışanlar ile emekli olmak isteyen yaşlı çalışanlar arasında ayrım yapmada başarısızdır (McNair, 2011: 27).

Yaşlı çalışanlar, iş geçmişleri, sosyo-ekonomik durumları ve aile yapıları açısından farklılıklar göstermektedir. Çalışmak ya da çalışma yaşamında kariyerlerini sürdürmek için farklı engellere sahiplerdir. Ancak, toplumsal normlar ve yaş önyargısı neredeyse tüm yaşlı çalışanları etkilemektedir. Nüfus ve işgücü yaşlandıkça, işverenlerin yaşlı çalışanların gelişmesini engelleyen yaş önyargılarıyla başa çıkmaları ve her yaştan ve evreden çalışanlara kariyerlerinde gelişme ve ilerlemeleri için fırsatlar sunmaları gerekecektir. Ayrıca, yaşlı çalışanların aktarılabilir deneyim ve becerilerinden en iyi biçimde yararlanmak için işe alma faaliyetleri uyarlanıp biçimlendirilmelidir (Lincoln, 2017: 8).

Endüstri 4.0 ortamında hızla değișen koşulların etkisi altında, rutin görevleri yerine getirmek ve standartlaştırılmış becerilere sahip olmak yeterli olmayacaktır. Belirsiz durumlarda karmaşık sorunlar ortaya çıkarsa, çalışanlar buna müdahale etmek zorunda kalacaktır. $\mathrm{Bu}$ nedenle, dijitalleşmiş bir dünyada işgücünün uyumunu sağlayabilmek için daha farklı becerilerin geliştirilmesi ve bunun için çalışanlara eğitim olanaklarının sunulması gerekmektedir. Özellikle, bireysel ve sosyal beceriler eskiye göre daha fazla dikkat çekmektedir. Bu bağlamda, dijitalleşme ve yaşlanan işgücü nedeniyle çalışanların yüksek teknik zorluklarla mücadele edebilmesi için iletişim becerilerinin yanı sıra, uzmanlarla işbirliği içerisinde olmak giderek daha önemli hale gelmektedir. Sonuç olarak, dijitalleşme çağında yaşlanan işgücünü desteklemek için dört araştırma alanı vurgulanmaktadır (Schinner ve diğerleri, 2017: 548):

- Koordinasyon odaklı yetkinlik kontrol sistemleri,
- $\quad$ iletişim ve davranışta değişiklikler,

- teknoloji kabulünden dönüşüm kabulüne giden yol,

- $\quad$ işbirliği için takım çalışması.

İşletmeler mevcut kurumsal yeterlilik portföylerini analiz ettikleri gibi, yaşlı çalışanların sahip oldukları bilgi, beceri ve deneyimlerinin verimli bir biçimde eşgüdümü için onların bireysel yetkinliklerini de analiz etmek zorundadır. Örgütsel gereklilikler ve bireysel yetkinliklerin yanı sıra, teknoloji ile bireysel yetkinlikler arasındaki uyumu yönlendirmeye yardımcı olan koordinasyon odaklı yetkinlik kontrol sistemleri endüstriyel rekabet gücünü korumak için anahtar bir araçtır. Ayrıca, siber fiziksel sistemler ve robotlar yaygın bir otomasyon yaratmasına rağmen, yaşlanan işgücünün istihdam edilebilirliğini korumaya da yardımcı olabilirler. Amaç, işletmelerin insan kaynaklarını en iyi biçimde koordine etmektir. $\mathrm{Bu}$ nedenle, deneyime dayalı mesleki yeterliliklerin yanı sıra, çalışanların yöntemsel, sosyal ve öz-yönetim yetkinlikleri hakkında da bilgi sahibi olmak gerekmektedir (Schinner ve diğerleri, 2017: 548).

Sistem karmaşıklığının artması, fiziksel çalışma ortamının giderek daha fazla otomatik hale gelmesi nedeniyle, Endüstri 4.0 'da yeni işlerin bilgi yoğun ve karmaşık bilgiyi uygulama, ilgili bilgileri araştırma, yeni bilgi oluşturma ve bilgi aktarmayı gerektirmesi yukarıda tartışılmıştır. Buna ek olarak, piyasalar bunu talep ettikçe ve üretim teknolojisi daha küçük parti büyüklüklerinin ve özelleştirilmiş ürünlerin üretilmesini sağlayabildiğinden, kuruluşlar içinde ve arasında, paydaşlar arasında ve hatta özel müşterilerle üretim yapan kuruluşlar arasındaki etkileșimin artması beklenebilir. Yaşlı çalışanların bu tür işlerde hiçbir dezavantajı bulunmamaktadır. Aksine, deneyimlerine ve genellikle artan örgütsel ve sosyal becerilerine dayanarak daha iyi performans gösterebilirler. 2014 yılında bir Alman araştırması, Endüstri 4.0'ın uygulanması için gerekli olan özel yetkinlikleri 
ve becerileri saptamıștır. Araştırmaya göre, yaşam boyu öğrenme (\%86), disiplinler arası düşünme ve eylem (\%77), bilişim yeterlilikleri (\%76), makineler ve ağ bağlantılı sistemler ile kalıcı olarak değişim yeteneği (\%75) ile sorun çözme ve optimizasyon becerisi (\%75) en önemli beceriler olarak görülmektedir. Daha sonra, sistem bilgisi (\%72), giderek karmaşıklaşan iş süreçlerinin kontrolü (\%71), dolaylı kişilerle çalışma yeteneği (\%65), inovasyon süreçlerine yapısal katılım ve inovasyon süreçlerinin tasarımı (\%61), iş akışları koordinasyonunun arttırılması (\%60) ve bağımsız karar verme (\%53) becerilerinin yanı sıra artan sosyal beceriler (\%43) gerekli beceriler olarak görülmektedir (Schlund ve diğerleri, 2014: 5,6,7; Wolf ve diğerleri, 2018: 71). Diğer yandan, güç ya da ince motor beceriler gibi yüksek fiziksel yetenekler gelecekteki çalışmalar için artık temel beceriler olarak görülmemektedir. Dünya Ekonomik Forumu'nun raporuna göre, fiziksel yeteneklerin öneminin azalması beklenen işlerin oranı \%27 olarak belirlenmiştir (World Economic Forum, 2016: 24,73).

Fiziksel yeteneklere ve becerilere ihtiyaç azaldıkça ve bilişsel olarak sosyal beceriler ya sabit kalmakta ya da artmakta olduğundan, yaşlı çalışanlar gelecekteki endüstriyel iş ortamlarında çalışmak için yeterli özelliklere sahip olmalıdır. Wolf ve diğerleri (2018) tarafından gerçekleştirilen araştırmada, yaşlı çalışanlarda birçok önemli yeteneğin çok yüksek olduğunu göstermektedir. Özellikle karmaşık durumlarda bağımsız karar verme (\%78), sistem bilgisi ve süreç anlayışı (\%73), sosyallik ve takım çalışması (\%69), disiplinler arası düşünme (\%67), sorun çözme ve koordinasyon becerilerinin (\%65) yaşlı çalışanlarda güçlü olduğu görülmüştür. Buna karşılık, BİT becerileri, yeni teknolojilerle etkileşim ve değişim ile inovasyona katılım ve yaşam boyu öğrenme becerileri yaşlı çalıșanlarda düşük düzeyde kalmıștır. Yaşlıların Endüstri 4.0 için ihtiyaç duydukları birçok yeteneği olduğu gibi onlara kapasitelerini gerçekleştirebilecekleri uygun çalışma ortamları sağlamak büyük önem taşımaktadır. Böyle çalışma ortamlarına ulaşmak için çeşitli önlemler ve çözümler üretilmelidir (Wolf ve diğerleri, 2018: 72).

\section{ENDÜSTRI 4.0 SÜRECINDE YAŞLI ÇALIŞANLARA YÖNELİK UYGULAMALAR}

Yenilik ve teknoloji, dijital dışlanmaya karşı en savunmasız kalan yaşlıların ekonomik ve sosyal entegrasyonu ve sağlığı için dönüştürücü bir etkiye sahip olabilmektedir. "Her Yaş İçin Toplum"un kurulmasını destekleyen Madrid Uluslararası Yaşlanma Eylem Planı (MIPAA), teknolojik kapasitenin yaşlıları güçlendirmek ve yaşlıların toplumda tam olarak içerilmesi ve katılımlarının sağlanması için fırsatlar sunduğunu kabul etmektedir. Teknoloji bireyleri bir araya getirmek için kullanılabilir ve böylece marjinalleşmenin, yalnızlığın ve yaşlar arasındaki ayrımın azaltılmasına katkıda bulunabilir. $\mathrm{Bu}$ nedenle yaşlı bireylerin teknoloji erişimine sahip olmalarını, bunlara katılmalarını ve teknolojik değişikliklere ayak uydurmalarını sağlamak için önlemler alınmalıdır (United Nations Department of Economic and Social Affairs Division For Social Policy and Department, 2018: 1).

Birçok gelişmiş işgücü piyasasında yaşlı çalışanlar orta-yüksek otomasyon riski altındadır ve düşük vasıflı çalışmaya yüksek oranda bağımlı olan ülkeler özellikle yüksek risk düzeyine sahiptir. Basu ve diğerleri (2018: 18)'ne göre, yaşlanma oranları daha yüksek olan ülkelerde yaşlı çalıșanların iş otomasyonu riski daha yüksektir. Özellikle Çin ve Vietnam'daki yaşlı çalışanların çalıştığ işlerin otomasyona uğrama riski çok yüksektir. Buna göre, Çin'deki yaşlı çalışanlar tarafından yapılan işlerin \% 76'sı ve Vietnam'da \% 69'u akıllı teknolojiler tarafından dönüştürülme riski altındadır. Ayrıca ileri düzeyde beceri gerektiren işlerin yoğunlaştığı ülkelerde bile, yaşlı çalışanların otomasyon karşısında savunmasız olabileceği belirtilmektedir. Almanya'da, yaşlı çalışanların sahip oldukları işlerin dijitalleştirilme riski \%57 iken, ABD'de \%52'dir. Kanada ve Avustralya en düşük 


\section{A. ÖKTEM ÖZGÜR - T. DEMIRBILLEK}

yaşlanma oranlarına ve sırasıyla $\% 47$ ve $\% 42$ olmak üzere, yaşlı çalışanlar bulunduğu işlerde daha düşük otomasyon riskine sahiptir. Ülkemiz açısından bakıldığında da, yaşlı çalışanların genellikle düşük vasıflı işlerde istihdam ediliyor olmasından dolayı, otomasyon riski \%60 düzeylerindedir. Mevcut sonuçlar ışığında, bir ülkenin yaşlı çalışanlara yönelik işgücü piyasası dinamiği, büyük ölçüde eğitim düzeyine, ürün ve hizmet sektörlerinin büyüklüğüne, devlet harcamalarına ve finansal düzenlemelerin gücüne bağlı olmaktadır. Bu bağlamda, refah harcamaları, sanayi değişimleri, finansal destek ile eğitim ve öğretim, yaşlı çalışanların yaygın şekilde işten çıkarılmalarının önlenmesinde kilit rol oynayacaktır. Uygun müdahaleler olmadan, toplumlar bu eğilimlerin bir sonucu olarak ciddi sorunlarla karşı karşıya kalmaktadır. İşsizlik ve eksik istihdam, eşitsizliğin artması ve ciddi vasıf yetersizliği gibi sorunlar, yaşlı çalışanların işletmelerin dijitalleșme ve otomasyon stratejilerine uygun şekilde dahil edilmediği ülkelerde daha da kötüleşecektir (Basu ve diğerleri, 2018: 15, 20).

Çalışma ortamlarını yaşlı çalışanların özel ihtiyaçlarına göre düzenlemek, ergonomik bulguları yaşla ilgili ihtiyaçlarla birleştiren yaş temelli iş ve işyeri tasarımının amacıdır. Daha önce de belirtildiği gibi yaşlı çalışanlar, yaşlanma sürecinde yaşadıkları çeşitli değişikliklerden kaynaklanan farklı beceri ve yeteneklere sahiptir. Bu değişikliklerin çoğu çalışabilirliklerini olumsuz yönde etkilemez. Aksine, disiplinlerarası düşünme, problem çözme ve süreç anlayışı gibi karmaşık ve dolaylı görevlerdeki artan deneyimleri ve yetkinlikleri, onları gelecekteki işler için değerli bir kaynağa dönüştürür. Potansiyellerini gerçekleştirmelerini sağlamak için farklı ihtiyaçlarını ve ön koşullarını ele alan bir çalışma ortamına ihtiyaçları vardır. Dikkate alınması gereken önemli faktörler şunlardır (Ilmarinen, 2005: 252; Wolf ve diğerleri, 2018: 72):

- İs organizasyonu: İșin organizasyonu içerisinde, düzenli bir konsantrasyon gerektiren ve çok karmașı, soyut ve tamamen yeni iş görevleri gerektiren monoton iş görevlerinin yaşlı çalışanlara verilmesi önlenmelidir. Ayrıca, zamana ya da performans baskısına sahip yüksek iş yüklerinden yaşlı çalışanlar korunmalıdır.

- Meyer (2007) tarafindan yapılan bir araştırmada, iş organizasyonunu değiștiren ve 40 yaş üzerindeki çalışanların daha yüksek bir paya sahip olduğu işletmelerde, işyeri düzenlemesi olmayan işletmelere klyasla BİT'e uyum sağlama ve verimliliğin daha yüksek olduğu saptanmıștır (Meyer, 2007: 15).

- Calışma alanı: Özellikle azalan görsel kapasite ve aydınlatma ya da iklim gibi çevresel koşullara karşı savunmasızlık daha ayrıntılı olarak ele alınmalıdır.

- Teknoloji ve işletme araçları: Yaşlı çalışanların farklı azalan yetenekleri kısmen teknoloji tarafından telafi edilebilir. Azalan bir görme duyusu, uyarlanabilir semboller, kontrastlar ve bir renk şeması ile giderilebilir. Destekleyici teknolojiler, yardım sistemleri ve insanmakine arayüzleri, daha az düzeyde BİT becerileri olan kullanıcıların ve yaşlı çalışanların sahip olabileceği becerileri telafi etmeleri için kolay, sezgisel ve kullanıcı ihtiyaçlarına göre tasarlanabilir.

- Insan faktörleri: Taşınacak, çekilecek ya da itilebilecek ağır yükler ile birlikte fiziksel kuvvet gerektiren çalışmanın yanı sıra yüksek zorlayıcı güç ve ani yük noktaları tamamen ortadan kaldırılmalıdır. Ayrıca zorlayıcı duruşlar, daha uzun statik kas çalışması ve tek taraflı zorlanma yaşlı çalışanlar açısından ciddi bir sorundur. Üstelik, optimal olmayan işlere ve vücut duruşlarına uyum sağlama becerilerinin yoğun olarak azalması nedeniyle, bireysel çalışma alanları ve farklı vücut formlarının yaşlı çalışanlar için iş ve işyeri tasarımında dikkate alınması daha önemlidir.

- Calışma ve mola süresi: Yaş arttıkça değișen biyo-ritimden dolayı, özellikle 
vardiya ve gece çalışmasından kaçınılmalıdır. İyilik halini sürdürmek için uygun molalar büyük önem taşımaktadır. Ayrıca esnek çalıșma uygulanmalıdır.

Konumlandırma cihazları, robotlar ya da monoton görevlerin otomasyonu ile yaşlı çalışanların kuvvet ya da ince motor becerileri gibi fiziksel yetenekleri güçlendirilir ve fiziksel işle ilgili zorlanmaları azaltılır. İş ergonomisi artırılarak ve insan-makine etkileşiminde riskleri önleyerek artan iş güvenliği sağlanabilir. Sinyaller ve uyarı işaretleri çalışanların fiziksel özelliklerine göre uyarlanabilir. Özellikle işitme, görme veya diğer duyusal bozukluklara karşı kontrast, işaretleme ve renklendirme gibi kullanıcı gereksinimlerine uyarlama yaşlı çalışanların çalışabilirliğini olumlu yönde etkileyebilmektedir (Kleindienst ve diğerleri, 2016: 3).

\section{SONUÇ}

Piyasa taleplerinin, teknolojinin ve işgücünün değişmesinden dolayı, işgücü piyasası yeni zorluklarla karşı karşıyadır. Söz konusu değişiklikler, iş ile ilgili görevlerde farklılaşmaya yol açtığından, gerekli işgücü becerilerinin ve yeterliliklerinin de yenilenmesine neden olmaktadır. Her ne kadar dijitalleşmenin, üretim sürecinde işlerin yok olmasına ve işgücünün işsiz kalmasına neden olacağı öngörülse de, insan faktörü geleceğin işletmelerinde merkezi bir rol oynamaya devam edecektir. Ancak, daha karmaşık görevleri yerine getirmek için çalışanlar, yardımcı teknolojiler ve yardımcı sistemlerle büyük ölçüde işbirliği içinde olacaktır. Özellikle bilișsel görevlerde desteğe ve işbirliğine olan ihtiyaç artacaktır. Diğer yandan, işletmeler değişken piyasalarda hızla değişen talepleri karşlamak zorunda olmalarının yanı sıra, demografik değişim ve nüfusun yaşlanması gibi doğal ve sosyal çevrelerindeki dıș sorunlarla daha fazla ilgilenmek durumunda kalacaklardır. İnsanteknoloji etkileşiminde, yenilikçi destek teknolojileri, yaşlı çalışanların çalışmalarını kolaylaştırmak için çok önemli bir ölçü olabilmektedir. Yardım sistemleri, BİT, robotik ve otomasyon yoluyla fiziksel destek, çalıșanların ve özellikle yașlı çalıșanların kendi potansiyellerini gerçekleştirmelerine ve fiziksel veya bilişsel yetersizliklerini telafi etmelerine olanak sağlayabilmektedir.

Yaşlı çalışanların dijital beceriler kazanmalarını sağlamak için yaşam boyu öğrenme ve sürekli eğitime yatırım yapılmalıdır. İşgücünü doğru nitelikler ve becerilerle donatmak için uygun bir mesleki eğitim sisteminin sağlanması ve yaşa uygun insan kaynakları yönetimi, çalışanların istihdamda verimli bir biçimde kalması için önemli faktörlerdir. Yașlanan nüfus ortalaması ve nitelikli işgücü kıtlığı arttığında, yüksek potansiyele sahip yaşlı işgücünün kullanılması, sürdürülebilir bir insan kaynakları yönetimi için esas olarak gereklidir. Yaşlı işgücünün çalışmasını desteklemek için iş ve işyeri tasarımının, çalışanlar yaşlandıkça değişen ihtiyaçlarına duyarlı, sosyal olarak kabul edilebilir ve kapsayıcı bir şekilde uyum tesis etmesi gerekir.

\section{REFERANSLAR}

Acemoglu, D., ve Restrepo, P. (2018). Demographics and Automation. Nber Working Paper Series, National Bureau of Economic Research, Working Paper 24421.

Aulbur, W., Arvind, Cj., ve Rishi, B. (2016). Skill Development for Industry 4.0. BRICS Skill Development Working Group.
Axelrad, H., Luski, I. ve Miki, M. (2013). Difficulties of Integrating Older Workers into the Labor Market: Exploring the Israeli Labor Market. International Journal of Social Economics, 40(12), 1058-1076.

Basu, M., Sung, P., Hedrich, W., ve Chacko, L. (2018). The Twin Threats of Aging and Automation. Marsch \& McLennan Companies, Mercer. 


\section{A. ÖKTEM ÖZGÜR - T. DEMIRBILLEK}

Brettel, M., Friederichsen, N., Keller, M., ve Rosenberg, M. (2014). How Virtualization, Decentralization and Network Building Change the Manufacturing Landscape: An Industry 4.0 Perspective. World Academy of Science, Engineering and Technology International Journal of Mechanical, Aerospace, Industrial, Mechatronic and Manufacturing Engineering, 8(1), 2014, 37-44.

Czaja, S.J., Neil, C., Arthur, D. F., Christopher, H., Sankaran, N. N., Wendy, A. R., ve Joseph, S. (2006). Factors Predicting the Use of Technology: Findings From the Center for Research and Education on Aging and Technology Enhancement (CREATE). Psychol Aging, 21(2), 2006, 333-352.

Davies, R. (2015). Industry 4.0 Digitalisation for Productivity and Growth. European Parliamentary Research Service.

Degryse, C. (2016). Digitalisation of the Economy and Its Impact on Labour Markets. The European Trade Union Institute, Working Paper.

Department For Work \& Pensions. (2017). Fuller Working Lives Evidence Base 2017. Government Social Research, London, https://assets.publishing.service.gov.uk/gove rnment/uploads/system/uploads/attachmen t_data/file/648979/fuller-working-livesevidence-base-2017.pdf (19.02.2019).

Ege Bölgesi Sanayi Odası (EBSO). (2015), Sanayi 4.0. Ege Bölgesi Sanayiciler Odası Araştırma Müdürlüğü.

Gehrke, L., Rule, D., Bellmann, C., Dawood, D., Kulik, J., Kuhn, A.T., Moore, P., Siemes, S., Singh, L., ve Standley, M. (2015). Industry 4.0, A Discussion of Qualifications and Skills in the Factory of the Future: A German and American Perspective. Titelbild: VDI-Haus Düsseldorf.

Ilmarinen, J. (2005), Towards a Longer Worklife! Ageing and the Quality of Worklife in the European Union. Finnish Institute of Occupational Health, Ministry of Social Affairs and Health, Helsinki.
International Federation of Robotics. (2017), Executive Summary World Robotics 2017 Industrial Robots. https://ifr.org/downloads/press2018/Execu tive_Summary_WR_2018_Industrial_Robots.p df(17.02.2019).

Kahraman, H. Artırılmış Gerçeklik (Augmented Reality). https://www.endustri40.com/artirilmisgerceklik-augmented-reality/ (15.02.2019).

Kleindienst, M., Wolf, M., Ramsauer, C., ve Pammer-Schindler, V. (2016). Industry 4.0: What Workers Need and What ICT Can Give An Analysis. 16th International Conference on Knowledge Technologies and Data-driven Business (i-KNOW 2016), Graz, Austria, 1-6.

Kooij, T. A. M. (2010). Motivating Older Workers: A Lifespan Perspective on the Role of Perceived HR Practices.Vrije Universiteit Amsterdam.

https://research.vu.nl/ws/portalfiles/portal/ 42189832/9126.pdf (20.12.2019).

Lia, K.Z.H. ve Lindenberger, U. (2002). Relations Between Aging Sensory/Sensorimotor and Cognitive Functions. Neuroscience and Biobehavioral Reviews, 26, 777-783.

Lincoln, J. (2017). An Ageing Workforce in The Digital Era: Older Workers, Technology and Skills. Business in the Community, The Prince's Responsible Business Network, Tata Consultancy Services.

Lu, Y. (2017). Industry 4.0: A Survey on Technologies, Applications and Open Research Issues. Journal of Industrial Information Integration, 6, 2017, 1-10.

Marjanovic, U., Lalic, B., Delić, M., ve Tasic, N. (2017). Industry 4.0: Evidence from Transitional Economy. 9th Annual ICGBEEAH, 92-102.

Marmora, P. ve Ritter, M. (2014). Unemployment and the Retirement Decisions of Older Workers. Department of Economics DETU Working Paper 14-01. Philadelphia. 
Mcnair, S. (2011). Older People and Skills in a Changing Economy. UK Commission For Employment and Skills Briefing Paper Series.

Meyer, J. (2007). Older Workers and the Adoption of New Technologies. Zentrum für Europäische Wirtschaftsforschung $\mathrm{GmbH}$ Centre for European Economic Research, Discussion Paper No. 07-050.

Nagy, J, Oláh, J., Erdei, E., Máté, D., ve Popp, J., (2018). The Role and Impact of Industry 4.0 and the Internet of Things on the Business Strategy of the Value Chain-The Case of Hungary Sustainability.MDPI, Open Access Journal,10(10), 1-25.

United Nations, Department of Economic and Social Affairs Population Division. (2015). World Population Ageing 2015 Highlights.

United Nations, Department of Economic and Social Affairs Population Division. (2017). World Population Ageing 2017 Highlights.

United Nations, Department of Economic and Social Affairs Population Division. (2018). Why Are Digital Skills Critical For Older Persons?. 56th Commission for Social Development, Strategies For Eradicating Poverty to Achieve Sustainable Development For All.

OECD, (1998). Employment Outlook 1998. Organisation For Economic CoOperation and Development Publishing, Paris.

OECD, (2005). Ageing and Employment Policies Netherlands - Vieillissement et politiques de l'emploi. Organisation for Economic Co-Operation and Development (OECD).

OECD, (2013). Employment Outlook 2013. Organisation For Economic CoOperation and Development Publishing, Paris.

OECD. (2015). Promoting Active Ageing in the Digital Economy: Inclusion, Adaptation and Innovation 1-2 September, 2015. Summary of Main Points. https://www.oecd.org/sti/ieconomy/OECD_ GCOA\%20Report\%202015.pdf (19.02.2019).
OECD. (2016). Skills for a Digital World. Policy Brief on The Future of Work.

OECD. (2018). Employment Outlook 2018. Organisation For Economic CoOperation and Development Publishing, Paris.

OECD. (2019). Getting Skills Right: Future-Ready Adult Learning Systems, Getting Skills Right. Organisation For Economic CoOperation and Development Publishing, Paris.

Paelke, V. (2014). Augmented Reality in the Smart Factory Supporting Workers in an Industry 4.0. Environment, IEEE Emerging Technology and Factory Automation (ETFA), 2014.

Peeters, M.C.W. ve Van Emmerik H. (2008). An Introduction to the Work and Wellbeing of Older Workers From Managing Threats to Creating Opportunities, Journal of Managerial Psychology, 23 (4), 353-363.

Petrillo, A., De Felice, F., Cioffi, R., ve Zomparelli, F. (2018). Fourth Industrial Revolution: Current Practices, Challenges, and Opportunities. Digital Transformation in Smart Manufacturing. (Ed. A. Petrillo, R. Cioffi ve F. De Felice,), InTech Publication, Croatia, 120.

Rüßmann, M., Lorenz, M., Gerbert, P., Waldner, M., Justus,J., Engel, P., ve Harnisch M. (2015). Industry 4.0: The Future of Productivity and Growth in Manufacturing Industries, The Boston Consulting Group (BCG).

Schieber, F. (2003). Human Factors and Aging: Identifying and Compensating for AgeRelated Deficits in Sensory and Cognitive Function. Impact of Technology on Successful Aging, (Ed. K. W. Schaie ve N. Charness), Springer Publishing Company, Inc., 42-84.

Schinner, M., Valdez, A. C., Noll, E., Schaar, A. K., Letmathe, P., ve Ziefle, M. (2017). Industrie 4.0' and an Aging Workforce - A Discussion from a Psychological and a Managerial Perspective. Human Aspects of IT for the Aged Population Applications, Services and Contexts, (Ed. J. Zhou ve G. Salvendy), 


\section{A. ÖKTEM ÖZGÜR - T. DEMIRBILLEK}

Springer International Publishing AG, 537556.

Schlund, S., Hämmerle, M., ve Strolin T. (2014). Industrie 4.0 Eine Revolution der Arbeitsgestaltung, Ingenics AG. FraunhoferInstitut für Arbeitswirtschaft und Organisation IAO.

Shafiq, S. I., Sanin, C., Szczerbicki E., ve Toro, C. (2015). Virtual Engineering Object / Virtual Engineering Process: A specialized form of Cyber Physical System for Industrie 4.0. Procedia Computer Science,60, 2015, 11461155.

Siemens. (2013). Industry Journal Topics, Trends, and Technologies for Decision Makers in Manufacturing. Competencies for The Future of Manufacturing, (Ed. S. Russwurm), Siemens Industry Journal, 2, 11-25.
Thames, L., ve Schaefer D. (2016). Software-Defined Cloud Manufacturing for Industry 4.0. Procedia CIRP, 52, 12-17.

Wan, J., Cai, H. ve Zhou, K. (2015). Industrie 4.0: Enabling Technologies. 2015 International Conference on Intelligent Computing and Internet of Things (IC1T), 135140.

Wolf, M., Kleindienst, M., Ramsauer, C., Zierler, C., ve Winter E. (2018). Current and Future Industrial Challenges: Demographic Change and Measures For Elderly Workers In Industry 4.0. ANNALS of Faculty Engineering Hunedoara - International Journal of Engineering Tome XVI, Fascicule 1, 67-76.

World Economic Forum. (2016). The Future of Jobs Employment, Skills and Workforce Strategy for the Fourth Industrial Revolution. World Economic Forum. 